\title{
Unidade para Portadores de Germes Multirresistentes: elaboração de um protocolo de atendimento de pacientes
}

\author{
Multidrug-Resistant Germs Carriers Unit: elaboration of a \\ patients care protocol
}

\author{
Andréia Barcellos Teixeira Macedo' • Marina Junges² Deborah Bulegon Mello $^{3}$ Carem Gorniak Lovatto ${ }^{4}$ \\ Sônia Beatriz Coccaro de Souza ${ }^{5}$
}

\begin{abstract}
RESUMO
Objetiva-se descrever a elaboração de um protocolo para o atendimento de pacientes portadores de Germes Multirresistentes (GMR) em uma unidade de internação. Estudo de consenso entre especialistas, concebido em um hospital universitário. A amostra foi composta por enfermeiros do setor, pelos profissionais da Comissão de Controle de Infecção da instituição e por professores de uma universidade federal. As informações foram coletadas por meio de registro de reuniões sistemáticas. Elaborou-se um protocolo para o atendimento dos pacientes portadores através da definição de parâmetros para a área física, assistência em equipe multiprofissional, organização do trabalho da enfermagem, indicadores à serem acompanhados, entre outros. Concluí-se que no Brasil, poucas são as instituições que possuem características semelhantes para cuidados de pacientes portadores de GMR. A utilização de um protocolo fornece elementos norteadores para a organização do atendimento, padronizando o cuidado e qualificando a assistência.
\end{abstract}

Palavras-chave: Bactérias; Cuidados de Enfermagem; Precaução; Unidades de Internação; Infecção Hospitalar.

\begin{abstract}
The aim is to describe the protocol elaboration for the care of patients with Multidrug-Resistant Germs (MDR) in an care unit. Consensus study among specialists, conceived in a university hospital. The sample consisted of the sector nurses, the Infection Control Commission of the institution and professors from a federal university. The information was collected through systematic meeting records. A protocol was developed for the care of the patients with parameters about physical area, assistance in multiprofessional team, nursing work organization, indicators to be followed, among others. It concludes that in Brazil, there are few institutions that have similar characteristics for the patients care with MDR. The protocol use provides guiding elements for the care organization, standardizing care and qualifying care.
\end{abstract}

Keywords: Bacteria; Nursing Care; Precaution; Care Unit; Cross Infection.

${ }^{1}$ Doutoranda do Programa de Pós Graduação em Enfermagem da UFRGS. Enfermeira, Chefe da Unidade de Internação para Portadores de Germes multirresistentes do Hospital de Clínicas de Porto Alegre, Rio Grande do Sul, Brasil. email: abtmacedo@gmail.com. Autor correspondente.

2 Enfermeira da Unidade de Internação para Portadores de Germes multirresistentes do Hospital de Clínicas de Porto Alegre, Rio Grande do Sul, Brasil. E-mail: mjunges@ hcpa.edu.br

${ }^{3}$ Mestre em Enfermagem. Enfermeira da Unidade de Internação para Portadores de Germes multirresistentes do Hospital de Clínicas de Porto Alegre, Rio Grande do Sul, Brasil.E-mail: dbmello@hcpa.edu.br

${ }^{4}$ Mestre em Enfermagem, Enfermeira da Comissão de Controle de Infecção Hospitalar do Hospital de Clínicas de Porto Alegre, Rio Grande do Sul, Brasil. E-mail: clovatto@ hcpa.edu.br

${ }^{5}$ Doutora em Psiquiatria, Enfermeira, Docente da Universidade Federal do Rio Grande do Sul, Rio Grande do Sul, Brasil. E-mail ssouza@hcpa.edu.br 


\section{INTRODUÇÃO}

O surgimento dos antibióticos foi um marco na história da saúde mundial, revolucionando o tratamento de doenças infecciosas de alta letalidade. Entretanto, o uso indiscriminado e inadequado de antibióticos desencadeou o fenômeno da resistência bacteriana. Microrganismos multirresistentes são aqueles resistentes à diferentes classes de antimicrobianos testados em exames microbiológicos. As infecções causadas por estes microrganismos, principalmente em pacientes críticos, fazem com que a terapêutica não obtenha êxito, prolongando as internações hospitalares e aumentando a mortalidade ${ }^{1-2}$.

As infecções relacionadas à assistência à saúde estão entre as seis principais causas de óbito no Brasil, ao lado de outras doenças como as cardiovasculares, neoplasias, respiratórias e infectocontagiosas. O surgimento de organismos multirresistentes causa grande preocupação nos sistemas de saúde, especialmente a resistência das Enterobacterias aos carbapenêmicos. Infecções causadas por este microorganismo são difíceis de tratar e geralmente resultam em taxas de 40 a $50 \%$ de mortalidade. Os pacientes infectados necessitam de vários tipos de cuidados e geralmente possuem internações prolongadas ${ }^{3-4}$.

Uma série de medidas deve ser implantada nas instituições hospitalares visando a redução da transmissão dos GMR. Dentre elas, destaca-se o monitoramento dos patógenos multirresistentes de maior prevalência, a implantação de política de uso racional de antimicrobianos, promoção da higienização de mãos entre os profissionais, implantação de medidas de higienização do ambiente, utilização de quartos individuais ou medidas de coorte, aplicação da precaução de contato, entre outros ${ }^{5}$. Precaução de contato é o conjunto de medidas adotadas para reduzir o risco de transmissão de infecção através do contato direto com o paciente ou com superfícies potencialmente contaminadas ${ }^{6-7}$.

Determinar qual foi a estratégia mais eficaz para minimizar as tendências de aumento das taxas de resistência bacteriana e a disseminação dos GMR dentro das instituições, ainda tem sido tarefa difícil. Por este motivo, a Comissão de Controle de Infecção Hospitalar $(\mathrm{CClH})$ de um hospital universitário apostou na implantação de um setor específico para internação desta clientela.

Acredita-se que esta medida inovadora propicia benefícios no tratamento dos pacientes e reduz as taxas de transmissão cruzada, principalmente pela manutenção de uma equipe multidisciplinar treinada para este tipo de atendimento e focada nas medidas de prevenção da disseminação dos patógenos.

Como em toda mudança, logo após a oficialização da unidade, observou-se a necessidade de redefinir a organização do trabalho no setor. Diferente de outras especialidades, no sul do Brasil ainda se dispõe de poucas iniciativas de bloqueio epidemiológico através do isolamento dos pacientes com GMR em um único setor, o que proporcionou uma construção de conhecimento singular.

Para minimizar a ocorrência de erro durante a assistência ao paciente, é necessário existir um processo de gestão do cuidado, com educação continuada, e implementação de protocolos, guia de recomendação clínica e normas e rotinas, identificando ações que ajudem à evitar danos decorrentes da assistência com o paciente ${ }^{8}$. Optou-se pela criação de um protocolo, visando a padronização do cuidado e a redução da subjetividade entre os profissionais, facilitando o entendimento dos processos e promovendo uma interpretação mais objetiva da assistência.

Desta forma, o presente artigo tem o objetivo de descrever a elaboração de um protocolo para o atendimento de adultos portadores de Germes Multirresistentes (GMR) em uma unidade de internação. Acredita-se que é uma metodologia inovadora de assistência, principalmente na organização do trabalho da enfermagem, profissional que participa efetivamente no cuidado e na definição da organização do atendimento. Pretende-se contribuir para a prática no cuidado à esta clientela, apresentando uma experiência que vem apresentado resultados positivos no contexto hospitalar.

\section{MÉTODO}

Estudo de validação por consenso entre especialistas, o qual descreve a elaboração de um protocolo para atendimento de adultos portadores de GMR. Este método permite o alcance de opinião coletiva ou acordo entre especialistas a respeito de um fenômeno específico. As técnicas de consenso vêm sendo bastante utilizadas na enfermagem visando definir padrões de prática ${ }^{9-10}$.

Foi realizado em um hospital universitário público de direito privado do sul do Brasil, que possui 842 leitos e uma moderna estrutura para diagnóstico e tratamento de diversas patologias em 60 especialidades, contando com 6116 colaboradores. A unidade para portadores de GMR possui 34 leitos distribuídos em 18 quartos e consta com 48 colaboradores. Passou à atender esta clientela em 2012, ano em que se trabalhou na elaboração do protocolo de atendimento. Internam pacientes clínicos e cirúrgicos para tratamento pelo Sistema Único de Saúde (SUS).

Foram selecionados intencionalmente para a participação da elaboração do protocolo 10 enfermeiros contratados pela instituição, todos com larga experiência em atendimento assistencial, dentre eles a chefia do setor, 02 professores de uma universidade federal, 01 médico e 01 enfermeiro lotados na Comissão de Controle de Infecção Hospitalar e 01 profissional da área administrativa. A construção do protocolo ocorreu por meio de discussões, em reuniões sistemáticas, visando consenso entre os experts, e seguiu as etapas apresentadas no quadro 1 : 
Quadro 1: Etapas utilizadas para o desenvolvimento do Protocolo de atendimento ao paciente portador de germes multirresistentes. Porto Alegre, Rio Grande do Sul, Brasil, 2017.

\begin{tabular}{|l|l|}
\hline \multicolumn{1}{|c|}{ Etapas } & \multicolumn{1}{c|}{ Descrição } \\
\hline $\begin{array}{l}\mathbf{1}^{\circ} \text { Revisão da } \\
\text { literatura }\end{array}$ & $\begin{array}{l}\text { Realizou-se extensa busca nas bases de } \\
\text { dados à procura de artigos que tivessem } \\
\text { publicação sobre o tema e revisão dos } \\
\text { guidelines. Nas publicações não foi } \\
\text { localizado descrição de algum outro } \\
\text { local que disponibilizasse um setor para } \\
\text { pacientes com GMR. }\end{array}$ \\
\hline $\begin{array}{l}\mathbf{2}^{\circ} \text { visita técnica } \\
\text { Foram realizadas duas visitas técnicas, } \\
\text { ambos em instituições com alguns leitos } \\
\text { destinados para portadores de GMR. O } \\
\text { objetivo foi conhecer as rotinas, quadro } \\
\text { de pessoal e se a instituição possuía } \\
\text { algum protocolo de atendimento. }\end{array}$ \\
\hline $\begin{array}{l}\mathbf{2}^{\circ} \text { Mapeamento } \\
\text { das atividades, } \\
\text { cuidados } \\
\text { realizados, } \\
\text { definição de } \\
\text { parâmetros } \\
\text { e criação do } \\
\text { protocolo }\end{array}$ & $\begin{array}{l}\text { Baseados na experiência assistencial, } \\
\text { nas particularidades da área, nas } \\
\text { diretrizes institucionais e na literatura, } \\
\text { os especialistas mapearam as atividades } \\
\text { e cuidados que deveriam ser realizados } \\
\text { exclusivamente com os pacientes } \\
\text { portadores de GMR da unidade. Após } \\
\text { então, definiram o que seria parâmetro } \\
\text { ou diferencial neste setor, dados que } \\
\text { passariam a compor o protocolo e as } \\
\text { recomendações pertinentes. }\end{array}$ \\
\hline $\begin{array}{l}\mathbf{3}^{\circ} \text { Implantação do } \\
\text { protocolo }\end{array}$ & $\begin{array}{l}\text { Ao longo do ano de 2012 o protocolo foi } \\
\text { gradativamente implantado, conforme } \\
\text { as atividades iam sendo descritas pelos } \\
\text { especialistas. }\end{array}$ \\
\hline
\end{tabular}

Fonte: dados da pesquisa.

A utilização do protocolo demandou um trabalho de sensibilização e capacitação dos profissionais do setor, visto que gerou um processo de mudança na organização do trabalho

Esta pesquisa foi aprovada pelo Comitê de Ética em pesquisa, sob número 93563. Os autores assinaram um Termo de Compromisso para Utilização de Dados, para ter acesso às minutas das reuniões de trabalho entre experts, comprometendo-se em preservar a privacidade e $o$ anonimato dos envolvidos.

\section{RESULTADOS}

O resultado deste estudo foi a elaboração de um protocolo para atendimento de pacientes portadores de GMR em uma unidade de internação, o qual foi didaticamente dividido em 5 capítulos apresentados a seguir:

\section{Critérios para internação na unidade}

Os fatores de risco associados à aquisição de infecções, de modo geral, podem estar relacionados às características de saúde do próprio paciente, ao tratamento proposto e ao ambiente hospitalar, sendo que a definição dos microrganismos resistentes depende da necessidade e do perfil de sensibilidade de cada instituição. Neste sentido, as instituições devem definir estratégias para reduzir a transmissão de bactérias multirresistentes no âmbito hospitalar ${ }^{3-11}$. São definidos como GMR na instituição os seguintes microrganismos: enterobactéria resistente aos carbapenêmicos, Clostridium difficile, Acinetobacter spp. resistente aos carbapenêmicos, Pseudomonas aeruginosa resistente aos carbapenêmicos, MRSA (Staphylococcus aureus resistentes à oxacilina) e Enterococcus spp. resistente à vancomicina ${ }^{5}$.

A instalação e liberação das medidas, assim como a triagem dos candidatos à internarem nesta unidade são de responsabilidade da $\mathrm{CClH}$ da instituição, através das ações descritas no Plano de Prevenção e Controle de Infecções Hospitalares ${ }^{5}$. A unidade para portadores de GMR receberá pacientes clínicos, cirúrgicos e de especialidades médicas, colonizados ou infectados por GMR e o controle dos pacientes será realizado através de uma lista alimentada pela CCIH denominada "Lista de portadores de GMR", a qual será amplamente divulgada entre os setores da instituição.

Pacientes com cultura positiva para os germes acima serão informados à $\mathrm{CCIH}$ pelo laboratório de microbiologia. A partir dessa informação inicial, todos os pacientes portadores de GMR serão identificados no sistema informatizado da instituição com cor azul. Um profissional da $\mathrm{CClH}$ notificará a área em que o paciente está internado (orientando a implantação da precaução de contato) através de contato telefônico com o enfermeiro do turno e registro da positivação no prontuário eletrônico. Caso ocorra indicação de internação, o nome será incluído na lista de pacientes aguardando leito no setor.

Entende-se que a eficácia do processo ocorre a partir da comunicação efetiva entre os membros envolvidos, da $\mathrm{CCIH}$ até os profissionais que se encontram na ponta, na assistência, tanto por telefone e email. Assim, diariamente circulará entre as chefias dos diversos setores da instituição e enfermeiros da unidade para GMR o email da "Lista de Pacientes portadores de GMR" e a "Lista de Pendências da CCIH", a qual se encontra dividida em pacientes da pediatria, adultos e tratamento intensivo. O sistema informatizado também disparará um email automático informando a entrada na instituição do paciente que já possui o diagnóstico do GMR, facilitando a visibilidade e o rastreamento do mesmo. Desta forma, o processo ficará muito bem registrado e os encaminhamentos podem ser dados pela supervisora de enfermagem, profissional responsável pela administração dos leitos nos finais de semana, feriados e período noturno. Nestes momentos de horário não comercial, a $\mathrm{CCIH}$ trabalhará em regime de sobreaviso, podendo auxiliar em caso de dúvidas.

\section{Equipe assistencial}

O atendimento será realizado por uma equipe multidisciplinar. Os pacientes seguirão internados na sua equipe médica de origem, os quais poderão contar com o apoio da $\mathrm{CCIH}$ para adequação do esquema terapêutico. 0 setor contará com 01 assistente social, 01 fisioterapeuta e 01 farmacêutico, além da equipe de enfermagem, e 
os casos serão discutidos através de rounds semanais, momento em que se avalia a situação de saúde do paciente e os encaminhamentos necessários. A psicologia realizará assessoramento através de consultoria, a qual será solicitada pelo enfermeiro. A nutrição na instituição é dividida por equipe médica e seguirá o acompanhamento.

O setor ainda contará com profissionais de apoio altamente capacitados, como a higienização, os quais os assumirão os cuidados de desinfecção do ambiente e a limpeza das superfícies com antisséptico padrão ${ }^{12}$.

\section{Área física e ambiente}

Cada enfermaria é composta por 02 leitos, 01 banheiro e 01 pequena sala de entrada. A organização do trabalho está sendo estruturada de forma à reduzir a troca de material e equipamentos entre os pacientes, com o objetivo de diminuir riscos de transmissão cruzada, assim como reduzir o transporte de material contaminado dentro do setor. Em cada quarto terá 01 Equipamento de Monitorização Não Invasiva (PNI) e 01 prancha de transferência. Nos banheiros ficarão instalados dispositivos para recolhimento de roupas usadas, lixeiras de resíduos biológicos e não biológicos e a cadeira de banho.

Para higiene de mãos, todos os quartos possuirão pia com sabão neutro na entrada e álcool espuma à beira de cada leito. Na entrada de cada quarto ficará uma bancada com aventais descartáveis e luvas de procedimento à disposição dos profissionais. Visando reduzir a circulação de pessoas no setor, o acesso à unidade ocorrerá através de um sistema de controle de acesso, com a liberação de entrada ativada pelo crachá do profissional da instituição ou do acompanhante. Para fins de orientação, foi fixada uma sinalização da porta principal, conforme figura 1. As medidas preventivas também serão sinalizadas na porta do quarto e na pasta do paciente.

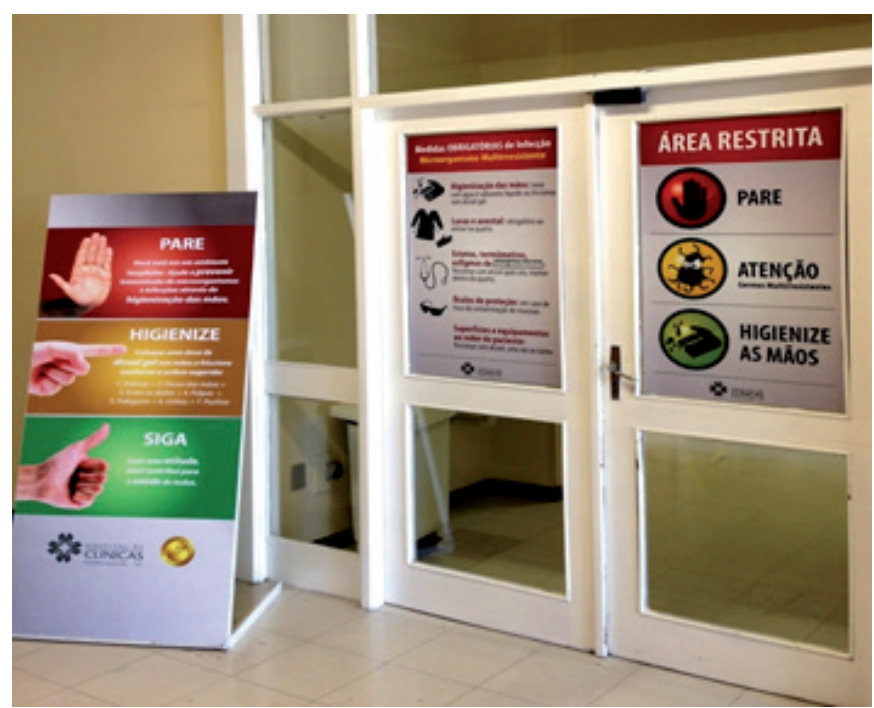

Figura 1. Foto da porta principal da unidade de internação para portadores de germes multirresistentes em um hospital universitário. Porto Alegre, Rio Grande do Sul, Brasil, 2017.

Fonte: imagem registrada no setor.

\section{Equipe de Enfermagem/Assistência aos pacientes}

A equipe de enfermagem deste setor é composta de 46 profissionais, sendo 10 enfermeiros e 36 técnicos e/ou auxiliares de enfermagem. Os profissionais são distribuídos conforme o quadro 2:

Quadro 2: Distribuição dos profissionais de enfermagem da unidade para portadores de germes multirresistentes por turnos. Porto Alegre, Rio Grande do Sul, Brasil, 2017.

\begin{tabular}{|c|c|c|}
\hline Turnos/profissionais & Enfermeiros & $\begin{array}{c}\text { Técnicos e } \\
\text { auxiliares de } \\
\text { enfermagem }\end{array}$ \\
\hline Manhã (7-13:15h) & 2 & 9 \\
\hline Tarde (13-19:15h) & 2 & $10^{\text {a }}$ \\
\hline Noturno (19-7:30h) & 3 & 15 \\
\hline Intermediário (19-1:15h) $^{\text {b }}$ & 1 & 1 \\
\hline VI Turno & 2 & - \\
\hline
\end{tabular}

Fonte: dados da pesquisa.

a- 0 turno da tarde conta com um reabilitado para atendimento das tarefas de farmácia e organização da medicação;

b- 0 noturno realiza jornadas de $12 \mathrm{~h}$ de plantão por $72 \mathrm{~h}$ de descanso, 0 total de profissionais é dividido em 3 grupos;

c- A instituição contrata enfermeiros para realizarem sua jornada de trabalho nos finais de semana e feriados, turno denominado VI turno.

A avaliação sistemática do nível de complexidade assistencial na instituição está em processo de implantação, e é realizada através do Sistema de Classificação de Pacientes de Perroca ${ }^{13}$. O planejamento do cuidado é realizado pelo enfermeiro, através da Sistematização da Assistência de Enfermagem (SAE). Inicia-se na chegada do paciente ao setor, através da realização da anamnese e exame físico. Durante a internação, o paciente é avaliado diariamente e em todos os turnos. Assim, torna-se possível realizar o exame físico, identificar os diagnósticos de enfermagem e organizar o cuidado através da prescrição eletrônica. Para melhor organização do trabalho, cada enfermeiro possuirá seus quartos fixos para evoluções e prescrições de enfermagem, sendo responsáveis por um exame físico mais detalhado e acompanhamento das lesões destes pacientes.

Os diagnósticos de enfermagem estabelecidos para o paciente com GMR visam minimizar o risco de transmissão cruzada do patógeno. Assim, após discussão entre os enfermeiros, optou-se por definir para esta clientela o diagnóstico de Risco para Infecção relacionado à exposição à patógenos aumentada. Dentre os cuidados, encontrase "Implementar cuidados com Precaução de contato". 0 registro das condições do paciente é realizado em evoluções diárias por sistemas: regulação neurológica (incluindo dor), oxigenação, regulação térmica, alimentação/hidratação, pele/mucosas, atividade/grau de dependência de cuidados.

Um dos objetivos de manter uma unidade exclusiva para pacientes portadores de GMR é o fato da equipe 
tornar-se altamente especializada, o que melhora a qualidade do cuidado ${ }^{5}$. Os profissionais de enfermagem receberão capacitações sistemáticas visando aquisição de novos conhecimentos, revisão de conhecimentos adquiridos previamente e a conscientização da importância da sua participação nos resultados do setor. Encontramse já programadas a capacitação no momento em que os profissionais são admitidos na unidade, capacitações anuais para atualização e informações específicas mensais através de rodada de conversa com os enfermeiros do setor e $\mathrm{CCIH}$.

Por tratar-se de um hospital universitário, outro fator importante é o papel de todos os profissionais na orientação dos estudantes e residentes que circularão no setor, reforçando a precaução de contato e a higienização das mãos.

Em relação aos indicadores, definiu-se como prioridade para análise e acompanhamento neste setor, os casos de infecção urinária em pacientes com sonda vesical, de infecção de corrente sanguínea em pacientes com cateter central, as taxas de higienização de mãos e de utilização da precaução de contato, trabalho realizado por uma enfermeira da $\mathrm{CClH}$. Com estes dados em mãos, ações serão planejadas em conjunto com a equipe da unidade para melhorar indicadores com oscilações no período.

\section{Familiares e acompanhantes}

A entrada dos familiares e acompanhantes será organizada para que ocorra redução de pessoas circulando no setor, mas ao mesmo tempo, propiciar que mantenhase um familiar de referência para o paciente e para a equipe assistencial, podendo também iniciar, o mais breve possível, as orientações e o treinamento para alta. No início da internação ocorrerá o fornecimento de um "Cartão de Acompanhante", o qual liberará a entrada de um familiar (ou acompanhante) por vez, sendo que o paciente poderá permanecer acompanhado durante 24horas, por uma pessoa de sua escolha, com a troca do acompanhante no saguão do hospital. Esta atividade será organizada pelo auxiliar administrativo do setor, que orientará as rotinas quanto à entrada e permanência no setor. Nesta unidade não haverá horário de visitas, como as demais da instituição e situações especiais serão avaliadas pelos enfermeiros do turno.

Apesar da utilização de medidas restritivas em relação à circulação de familiares e visitantes, a equipe assistencial oferecerá vários momentos de orientação para os familiares e pacientes. Serão fornecidas orientações à beira do leito, em atendimento individualizado, material impresso em forma de folder de orientação, e orientações em grupo, por meio de um Grupo de Orientação aos Familiares, iniciando na chegada do paciente ao setor. Estas orientações abordarão as medidas para redução da transmissão dos GMR e bloqueio epidemiológico, um histórico e panorama sobre a situação do GMR, sobre rotinas da unidade e também será fornecido treinamento dos cuidados ao paciente, iniciando precocemente o preparo para alta. Entende-se que todos os profissionais devem possuir conhecimento e se sentirem empoderados para o fornecimento destas orientações durante toda a internação.

Em situações especiais, os enfermeiros, assistente social ou equipe médica poderão liberar a entrada no setor de outros familiares, na condição de visitante. Para que seja do conhecimento de todos, esta liberação será realizada por email, endereçado à recepção e à grupo formado pelos profissionais do setor.

\section{DISCUSSÃO}

A construção do protocolo de atendimento para pacientes portadores de GMR possibilitou a padronização dos cuidados a esta clientela. A literatura aponta que a utilização de guias e manuais na enfermagem pode agregar uma série de benefícios, tais como servir de fonte de referência objetiva, clara e acessível à interpretação das orientações, otimizar reuniões e treinamentos, bem como harmonizar e profissionalizar o ambiente de trabalho ${ }^{14}$.

Os resultados iniciais demonstraram um decréscimo significativo do GMR, principalmente nas infecções causadas pelo Enterococcus spp. resistente à vancomicina e Pseudomonas aeruginosa resistente aos carbapenêmicos. Estes resultados podem estar ligados ao comprometimento desta equipe com a higienização das mãos, que chegou a uma taxa de $95 \%$ no período estudado ${ }^{15}$.

Quanto ao nível de complexidade assistencial, constatou que 18 (22,5\%) pacientes necessitavam de cuidados intermediários, 35 (43,7\%) de cuidados semiintensivos e $27(33,8 \%)$ de cuidados intensivos ${ }^{16}$. Diferente do que ocorre em unidades cirúrgicas ou de cuidados eletivos, não observa-se diferença do volume de cuidados nos sete dias da semana, entre os três turnos de trabalho ou modificações sazonais.

Entende-se que existe a necessidade de redimensionamento da equipe de enfermagem frente á uma modificação do perfil dos pacientes que passaram a internar no setor, principalmente do pessoal de nível médio, fato que já encontra-se em discussão. Observou-se que o número de horas de afastamento por doença aumentou nesta equipe, com taxa de absenteísmo em torno de 4,5\% em 2015 (3,78\% em 2012), enquanto a meta institucional é de valores inferiores a $2,95 \%^{(17)}$.

O grupo de familiares vem sendo uma boa estratégia para envolver o acompanhante no cuidado através da disponibilização do conhecimento necessário. Identificouse que há o reconhecimento do ambiente como contaminado e que os familiares reconhecem a importância das medidas para redução da transmissão do GMR, entendendo também que estes cuidados reduzem a chance de contaminação do paciente por outro germe ${ }^{18}$. 


\section{CONCLUSÃO}

A criação de um setor específico para atendimento de pacientes portadores de GMR trouxe melhorias para o cuidado e a redução da transmissão de GMR na instituição.

Entende-se que a especialização de uma equipe contribui para os resultados, mas medidas como a tomada de decisão em conjunto, conhecimento e reconhecimento do trabalho realizado, fazem aumentar o comprometimento do grupo, gerando qualificação e segurança na assistência ao paciente e consequentemente, resultados favoráveis. 0 atendimento à esta clientela também propicia campo de ensino e pesquisa.

\section{REFERÊNCIAS}

1. Ministério da Saúde (BR). Nota Técnica No 1/2010: Medidas para identificação, prevenção e controle de infecções relacionadas à assistência à saúde por microrganismos multirresistentes. Brasilia (Brasil): Ministério da saúde, 2010, 25p.

2. Sader HS, Gales AC, Pfaller MA, Mendes RE, Zoccoli C, Barth A et al. Pathogen frequency and resistance patterns in brazilian hospitals: summary of results from three years of the SENTRY anti- microbial surveillance program. Braz J Infect Dis [Internet]. 2001[acesso em 5 set 2016]; 5(4):200-14. Disponível em: http://www.scielo.br/scielo.php?pid=S1413$86702001000400006 \&$ script=sci_arttext \&tlng=pt.

3. Centers for Disease Control. Facility Guidance for Control of Carbapenem-resistant Enterobacteriaceae (CRE). [Internet]. 2015 [acesso em 15 ago 2016]. 24p. Disponível em: https:// www.cdc.gov/hai/pdfs/cre/CRE-guidance-508.pdf.

4. Schwaber $M$, Lev B, Israeli $A$, et al. Containment of a countrywide outbreak of carbapenemresistant klebsiella pneumoniae in Israeli hospitals via a nationally implemented intervention. Clin Infect Dis [Internet]. 2011 [acesso em 15 ago 2016]X 52(7):848855. Disponível em https://www.ncbi. nlm.nih.gov/pubmed/21317398.

5. Kuplich NM et AL. Política de prevenção da disseminação de germes multirresistentes no Hospital de Clínicas de Porto Alegre. Rev HCPA [Internet]. [acesso em 10 set 2016]. 2011;31(1). Disponível em: http://seer.ufrgs.br/hcpa/article/ viewFile/15037/11541.

6. Figueredo RM, Leite C. As práticas de precauções/isolamento a partir do diagnóstico de internação em unidade de moléstias infecciosas. Rev. Eletr. Enf. [Internet]. 2006 [acesso em 20 ago 2016]; 8(3):358-62. Disponível em: http://www. fen.ufg.br/revista/revista8_3/v8n3a06.htm.

7. Siegel JD, Rhinehart E, Jackson M, et al. Health Care Infection Control Practices. Advisory Committee.2007 Guideline for Isolation Precautions: Preventing Transmission of Infectious Agents in Health Care Settings. Am J Infect Control. 2007;35(10 Suppl 2): S65-164.

8. Hooton TM, Bradley SF, Cardenas DD, Colgan R, Geerlings SE, Rice JC, et al. Diagnosis, prevention, and treatment of catheter-associated urinary tract infection in adults: 2009 International Clinical Practice Guidelines from the Infectious Diseases Society of America. Clin Infect Dis. 2010; 50(5):625-63.
9. Lunney M, McGuire M, Endozo N, Mclntosh-Waddy D. Consensus-Validation Study Identifies Relevant Nursing Diagnoses, Nursing Interventions, and Health Outcomes for People with Traumatic Brain Injuries. Rehabilitation Nursing [Internet]. 2010 [acesso em 25 ago 2016]; 35(4):161166. Disponível em: http://onlinelibrary.wiley.com/ doi/10.1002/j.2048-7940.2010.tb00042.x/abstract.

10. Azzolin K, Souza E, Ruschel K, Mussi C, Lucena A, Rabelo E. Consensus on nursing diagnoses, interventions and outcomes for home care of patients with heart failure. Rev. Gaúcha Enferm [Internet]. 2012; 33(4):56-63. Disponível em: http://www.scielo.br/scielo.php?script=sci_ arttext\&pid=S1983-14472012000400007.

11. Mantese OC, Paula A, Mores AB, Moreira TA, Guerra MLLS, Brandileone MCC. Prevalência de sorotipos e resistência antimicrobiana de cepas invasivas do Streptococcus pneumoniae. J Pediatr [Internet]. 2003 [acesso em 20 ago 2016]; 79(6):537-542. Disponível em http://www.scielo.br/ pdf/jped/v79n6/v79n6a13.pdf.

12. Brasil. Agência Nacional de Vigilância Sanitária. Manual de Segurança do Paciente em Serviços de Saúde: limpeza e desinfecção de superfícies. Brasília (DF): MS; 2010,120p.

13. Perroca MG. The new version of a patient classification instrument: assessment of psychometrics properties. J Adv Nurs [Internet]. 2013 [acesso em 20 ago 2016]; 69(8):1862-8. Disponível em https://www.ncbi.nlm.nih.gov/ pubmed/23157307.

14. Matsuda L, Meireles V, Gomes F, Saalfeld S, Molina R. Administrative instruments: nurses' perception in a school hospital. Cogitare enferm. [Internet]. 2010 [acesso em 25 ago 2016]; 15(1):117-123. Disponível em: http://revistas.ufpr.br/ cogitare/article/view/17182/11317.

15. Stumpfs, $D$ et al.The Impact of a Single Ward for Cohorting Patients with Infection due to Multidrug-Resistant Organisms. Infection Control and Hospital Epidemiology [Internet]. 2013 [acesso em 25 ago 2016]; 34(8):864-865. Disponível em: https://www.cambridge.org/core/journals/ infection-control-and-hospital-epidemiology/article/ the-impact-of-a-single-ward-for-cohorting-patientswith-infection-due-to-multidrug-resistant-organisms/ ACA16C53D0CD1137A8D18B2572BA7929.

16. Macedo A, Souza SBC, Gentilini MM, Graciotto A, Cortelini CLS. Classification of patients with multiresistant germs according to the degree of dependence on nursing care. Revista HCPA [Internet]. 2012 [acesso em 25 ago 2016]. Disponível em: https://www.hcpa.edu.br/content/view/1614/1123/.

17. Hospital de Clínicas de Porto Alegre (BR). Sistema de Informações Gerenciais - IG-BSC. Porto Alegre (RS): HCPA; 2015.

18. Marques RB et al. A compreensão dos familiares de pacientes portadores de germe multirresistente acerca do isolamento e das medidas de precaução. Revista Ciência \& Saúde [Internet]. 2014 [acesso em 15 ago 2016]; 7(3):131-147. Disponível em: http://revistaseletronicas.pucrs.br/ojs/index. php/faenfi/article/view/17367. 